plants used to brew home-made teas may contain pennyroyal oil, a highly neurotoxic and hepatotoxic agent. When mistakenly given to infants as a remedy for colic and other minor ailments, the chemical metabolites of the oil, pulegone and menthofuran, can deplete tissue enzymes and lead to multiorgan failure. The liver and brain are particularly vulnerable, and symptoms of mint tea poisoning include coma and convulsions. Other manifestations are cerebral edema, metabolic acidosis, hypoglycemia, gastrointestinal bleeding, and intravascular coagulopathy. Treatment consists of gastric lavage, activated charcoal, and N-acetylcysteine to replace hepatic glutathione depleted by the toxin. Hispanic parents especially, who frequently treat infants with homegrown herbs, should be warned of the hazards of certain mint plants. This report alerts physicians to the potential toxicity of mint teas and the inclusion of herbal remedies in the differential diagnosis of infantile epileptic encephalopathy.

\title{
PRENATAL COCAINE AND INFANT BEHAVIOR
}

The Brazelton Neonatal Behavioral Assessment Scales (BNBAS) were administered to 23 infants exposed to cocaine in utero and 29 nonexposed infants recruited from the low-risk nursery, Wayne State University Hospital, Detroit. Cocaine exposure was determined by quantitative analysis of the infant's meconium stool. Exposed infants performed less well than controls on 6 of the 7 BNBAS clusters, particularly in tests for autonomic stability. A doseresponse relationship was evident, with a negative effect of meconium cocaine concentration on motor, orientation, and regulation of state. (Delaney-Black V, Covington C, Ostrea E Jr et al. Prenatal cocaine and neonatal outcome: evaluation of dose-response relationship. Pediatrics Oct 1996;98:735-740). (Reprints: Virginia Delaney-Black MD, Children's Hospital of Michigan, 3901 Beaubien, Detroit, MI 48201).

COMMENT. Significant adverse behavioral effects may be demonstrated in neonates born to cocaine addicted mothers. Quantitative determination of cocaine exposure by meconium analysis is essential, since screening by history alone is found to be inadequate.

Three additional studies of the effects of prenatal cocaine on neurobehavior are summarized as follows. The Brazelton NBAScale, used at the Western Psychiatric Institute, University of Pittsburgh, showed impaired scores in motor maturity and tone, autonomic instability, and an increased number of abnormal reflexes on the 2nd day postpartum, but not at day 3 . (Richardson GA et al. The effects of prenatal cocaine use on neonatal neurobehavioral status. Neurotoxicol Teratol Sept/Oct 1996;18:519-528). Heavy cocaine exposure early in pregnancy was related to faster responsiveness on an infant visual expectancy test but poorer recognition memory and information processing in 464 inner-city, black infants tested at 6,12 , and 13 months in the Psychology Department, Wayne State University, Detroit, MI. (Jacobson SW et al. New evidence for neurobehavioral effects of in utero cocaine exposure. L Pediatr Oct 1996;129:581-590). The motor development of 28 infants exposed to cocaine in utero compared to that of an unexposed group followed from birth through 15 months at Boston University, Department of Physical Therapy and Child Development Unit, Children's Hospital, Boston, showed impairments in performance at 4 and 7 months of age but not at 15 months. However, all infants, both exposed and unexposed, were motor impaired when compared to norms, a reflection of the effects of poverty and malnutrition in inner-city infants. (Fetters L, Tronick EZ. Neuromotor 
development of cocaine-exposed and control infants from birth through 15 months: poor and poorer performance. Pediatrics Nov 1996;98:938-943). The combination of cocaine exposure and poor nutrition is a cumulative risk factor for impaired infantile motor performance in minority subjects and potentially detrimental to later neurocognitive development.

\section{ASYMPTOMATIC HEAVY LEAD EXPOSURE}

Three asymptomatic children, ages 34, 23, and 26 months, with blood lead levels $>100 \mathrm{mcg} / \mathrm{dL}$ on routine screening are reported from the Kennedy Krieger Institute and Department of Pediatrics, Johns Hopkins, Baltimore, MD. All suffered from pica and one was described as "hyper." Screening appears to be essential in at risk children if lead poisoning is to be detected and eradicated. (Davoli CT, Serwint JR, Chisolm JJ Jr. Asymptomatic children with venous lead levels $>100 \mathrm{mcg} / \mathrm{dL}$. Pediatrics Nov 1996;98:965-968). (Reprints: Cecilia T Davoli MD, Kennedy Krieger Institute, 707 North Broadway, Baltimore, MD 21205).

COMMENT. It is unfortunate that children must be used as "lead detectors" before lead violations in homes and schools are corrected and lead abatement instituted. Critics of routine screening at 6 months to 6 years must be impressed by this report and conclude that in certain populations, screening is the only way to prevent childhood morbidity and mortality from lead exposure.

\section{INFECTIOUS DISORDERS}

\section{NEUROCYSTICERCOSIS WITHOUT RISK FACTORS}

Two unusual cases of cysticercosis in children, ages 6 and 3 years, without risk factors or infected contacts, and five additional cases in children $<2$ years, are reported from Loyola University Chicago Stritch School of Medicine, Maywood, IL; University of Illinois at Chicago Medical Center; Children's Memorial Hospital, Chicago; and Centers for Disease Control and Prevention, Atlanta, GA. The source of infection was not identified in cases 1 and 2, and pork was never or only occasionally consumed. Both children were born and lived in Chicago. One had travelled to Ireland twice, where cysticercosis is not endemic. Cases 3 to 7 were born in the US, but had parents and other relatives from Latin America. Five patients had focal seizures and two had generalized seizures, as the presenting symptoms in 6 cases. One child presented with an inflamed, cystic, subcutaneous swelling on his back. An initial CT was negative, but a ring-enhancing lesion in the temporal lobe was found after seizures developed and before antiparasitic therapy was instituted. All other cases had positive CTs on admission. After treatment with dexamethasone for 3 days and praziquantel for 15 days, seizures did not recur. (Stamos JK, Rowley AH, Hahn YS, Chadwick EG, Schantz PM, Wilson M. Neurocysticercosis: report of unusual pediatric cases. Pediatrics Nov 1996;98:974-977). (Respond: Julie Kim Stamos MD, Section of Pediatric Infectious Diseases, Loyola University Medical Center, Department of Pediatrics, 2160 South First Ave, ET Bldg, 8th Floor, Maywood, IL 60153).

COMMENT. Neurocysticercosis in the US is rare, especially in children, but an increased incidence in the last decade is reported, even in patients who have never travelled to endemic areas. Taenia solium eggs may survive under 